\title{
NOG EENIGE BRONNEN
}

VOOR DE TAAL-, LAND- EN VOLKENKUNDE ONZER INDISCHE BEZITTINGEN,

\section{TE LONDEN,}

AANGEWEZEN DOOR

\section{A. B. COHEN STUART.}

Vol erkentelịjkheid jegens hen, die mij met mededeelingen van gelijken aard als de hier bedoelde zijn voorgegaan ${ }^{1}$, en mij daardoor den weg hebben gewezen tot hulpmiddelen van groote waarde voor mijne studie, heb ik gemeend, bij 't benuttigen van die aanwijzing, in zoover de omstandigheden het toelieten, ook van mijne zijde bedacht te moeten zijn op het belang van andere onderzoekers, en tot dat einde tijdens een kort verblijf te Londen, in Julij en Augustus jl., aanteekening gehouden van 't een en ander, wat hun welligt van eenige dienst zal kunnen zijn.

Een enkel woord van nadere opheldering omtrent het oogmerk van mijn bezoek te Londen zal van zelf leiden tot hetgeen ik verder mede te deelen heb. In de Voorrede van mijne uitgave der nieuw-Javaansche omwerking van de Bråtå-joedå gaf ik (blz. 33) den wensch te kennen, om later de uitgave van de Bråtå.joedå Kawi te beproeven, doch beklaagde mij tevens over het gemis van een' goeden tekst, daar ik wel verscheidene handschriften van de B.J. Kawi had kunnen magtig worden, maar daaronder slechts één ten naaste bij compleet, en juist dit bijzonder onnaauwkeurig, zoodat ik voor een groot deel van dat dichtwerk, inzonderheid van de laatste helft, tot één of twee zeer gebrekkige teksten beperkt was. Onder de overige, min of meer incomplete, codices was er geen, die mij toescheen meer vertrouwen te verdienen dan de fragmenten, door RAFFLEs in zijne

1 H. NeUbronner van Der tUUK, de Maleische handschriften in 't East India house te Londen, in het Tïdschr. voor Ned. Indië, 1849; Mr. s. KEIJZER, de Javaansche handschriften te Londen, in de Bïdragen tot de taal-, land- en volkenkunde van $N$. I., D. II, blz. 330, vlgg.

VI. (X) 
History of Java ( $8^{\mathrm{ro}}$ uitgave, Deel I, blz. 467, volgg.), in Engelsche transscriptie, uitgegeven, en in mijne Kritische aanteekeningen door letter $\mathrm{K}$ angeduid. Toen ik dus uit de lijst van den heer KeIJzer ontwaarde, dat er zich te Londen verscheidene MSS. van de $B . J . K w$. bevonden, waaronder drie in 't bezit van de Royal Asiatic Society, waarschijnlijk afkomstig uit de nalatenschap van RAFFLEs, werd hierdoor de wensch bij mij opgewekt, om mij in persoon te overtuigen van de betrekkelijke waarde dier MSS., en inzonderheid om te onderzoeken, of daaronder welligt hetzelfde handschrift te vinden was, waaraan de fragmenten van RAFFLes ontleend waren. Tot dit onderzoek vond ik thans gelegenheid, en zag het met het meest verblijdend gevolg bekroond.

In 't Britsch Museum moesten zich volgens den heer KEIJZER twee MSS. van de $B$. J. bevinden, en wel $N^{\circ} .12279$ en 12326 van de afdeeling Handschriften, het laatste echter in nieuw Javaansch. Het eerste, in klein $4^{\text {to }}$., lederen band, volgens aanteekeningen op het voorblad aangekocht van J. CRAWFURD, in Febr. 1842, en geschreven in A. J. $1741=$ A. D. 1814, bleek te zijn een compleet of nagenoeg compleet handschrift van de $B . J . K w$., met begin van Javaansche verklaring, maar vol van de grofste fouten, die de slordigheid en onkunde van een' afschrijver kunnen te weeg brengen, wanneer hij zijn origineel niet lezen $\mathrm{kan}$, en er veel te weinig van verstaat, om er zich door gissing uit te redden. Ik begon evenwel, met er de voornaamste varianten uit aan te teekenen, maar vond daar zoo weinig baat bij , dat ik alras begreep, mijn' hoogst beperkten tijd beter te kunnen besteden. - Het andere MS. was werkelijk een van de $B$. J. djarwå, waarvan ik reeds te ruim roorzien was, om daar nadere aandacht aan te kunnen wijden.

Onder de Javaansche MSS. van de Royal Asiatic Society vermeldt de heer KeIJzer, gelijk gezegd is, drie van B.J.Kw., waarvan echter een, $\mathrm{N}^{\circ}$. 15, geen $K w$., maar djarwå bleek te zijn. Zoo meen ik mij althans te herinneren; want tot mijn' spijt bemerk ik, daar geene aanteekening van te bezitten; maar zeker heb ik het MS. in handen gehad, en zou mij zeer bedriegen, als ik het om eene andere reden ter zijde gelegd had. De beide andere, $\mathrm{N}^{\circ}$. 11 en 31 , heb ik, dank zij de bekende welwillendheid van den heer REDHouse, Secretaris van 't genootschap, naar Nederland medegekregen, en thans vóór mij.

N. 11 bevat in klein folio, half lederen band, een' bijna com- 
pleten, zeer fijn en net geschreven' en ongemeen zuiveren tekst van de $B . J . K w$, , blijkens ontwijfelbare kenteekenen dezelfde, waaruit de fragmenten bij RAFFLEs in Engelsche transscriptie zijn afgedrukt. Het laatste gedeelte, strophe 658-97, is van eene andere hand en op ander papier geschreven dan 't vorige; wat, ondanks een klein verschil in de cijfers, voldoende verklaring vindt in de aanmerking van RAFFLES op blz. 522 , bij str. 656 , dat "hier de Javaansche handschriften van de $B$. J. eindigen, "en de volgende uittreksels ontleend zijn aan een MS., hem door “den Radja van Bali Beliling geschonken,” uit welk laatste dan waarschijnlijk het slot van onzen tekst is bijgeschreven. Deze loopt evenwel slechts tot str. 697, en eindigt daar, zonderling genoeg, boven aan een overigens onbeschreven blad (blz. 136 van 't MS.), midden in 't laatste gevecht tusschen ARDJOENA en aswattama; terwijl het uittreksel van RafFles uit het Balinesche MS. een twintigtal strophen verder, met str. 719, een behoorlijk afgesloten einde neemt. Welligt waren dus van dit MS. een of twee bladen verloren gegaan, toen het afschrift gemaakt werd. Meerdere bijzonderheden mogen bespaard blijven voor eene meer opzettelijke behandeling van de $B . J . K w$. - Achter dit dichtwerk volgt in 't zelfde kostbare bandje, na eenige witte bladen, $2^{\circ}$. (blz. 148-62) de Niti-sastra Kawi, van dezelfde hand en op hetzelfde papier als het eerste gedeelte van de $B$. J. $K w$.; daarna $3^{0}$. (blz. $171-243$ ) volgens opschrift de Falak Boedha Kawi (niet, zoo als de lijst van den heer кEIJZER heeft, Jalah Boeda), eene soort van astrologischen kalender, in een schrift geheel afwijkende van 't gewone Javaansche, met teekeningen van draken en andere, meest fabelachtige, voorwerpen, kruisvormige figuren met letters of cijfers er in, enz., vergezeld van een begin van transscriptie (of vertaling?) in Javaansch schrift: - onder de teekeningen dezelfde, welke voorkomen op plaat 27 en 28 van RAFFLEs' atlas, als "facsimile of signs "representing the division of the day and the pasar or market "days, - it. of the signs of the zodiac, - from an ancient MS. "in possession of the Tumunggung of Telaga in Cheribon:" waarschijnlijk is ons handschrift eene copie van datzelfde Tjeribonsche MS., en zijn daaraan de kleine afwijkingen tusschen de vóór ons liggende teekeningen en de platen van $R$. te wijten, die niet wel toelaten, ons MS. zelf voor het model van die platen te houden; - op pl. 27 vindt men tevens eenige staaltjes van 't hier bedoelde schrift, echter niet naauwkeurig overeenko- 
mende met dat van ons MS., hetwelk veel zwaarder en duidelijker is; - vervolgens $4^{\circ}$. een paar bladen $(246-62$, half beschreven) van 't zelfde (Tjeribonsche?) schrift, houdende volgens 't opschrift: "directions for obtaining success in war by attending to cer"tain positions and superstitions;" 5०. (blz. 268-89) verscheidene oud-Javaansche alphabetten (die blijkbaar tot modellen gediend hebben voor pl. 21 van RAFFLES), met voorbeelden van schrift en Javaansche transscriptie; benevens facsimile, transscriptie en verklaring van eenige inscripties op oude ringen en op de ruïnes van Soekoeh; $6^{\circ}$. (blz. 292-306) eene Javaansche beschrijving van Kawi- en nieuwere dichtmaten; $7^{\circ}$. (blz. 307-17) Goendlil djawi, d. i. Javaansch schrift zonder sandhangan's, met verklaringen (b. v. Esamanamanaranas

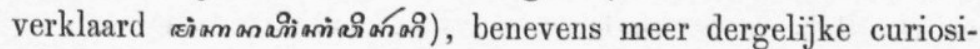
teiten en eenige gemengde opgaven. Het geheele bandje heeft het voorkomen van opzettelijk te zijn bijeengebragt ten behoeve van 't letterkundig gedeelte van RaFFLEs' Htstory of Java, maar bevat niettemin nog veel, wat een nader onderzoek ruimschoots waardig schijnt. ${ }^{1}$

$N^{\bullet}$. 31, een Javaansch lederen band, klein $4^{\text {to }}$, blijkens opschrift aan 't Genootschap geschonken door Lady RAFFLEs, den 6 Junij 1830 , bevat alleen de $B . J$. $K w$., van 't begin tot het einde, met nog een vijftal strophen achter aan 't slot, waarin o. a. gezegd wordt, dat het afschrift voltooid is op Zaturdag 23 Sawal van 't jaar $B e ́ 1720$, d. i. 24 Mei 1794. Het is geschreven op zwaar papier, met eene duidelijke, royale hand; maar de spelling is slordig, en de lezing zoo bedorven, dat het MS. alleen als bijkomend hulpmiddel eenige waarde heeft. I k kan niet denken, dat dit het bovenbedoelde Balinesche MS. zou zijn: zeker althans kan het niet tot model gediend hebben voor het laatste gedeelte van 't vorige handschrift, of de afschrijver zou het aanmerkelijk verbeterd hebben; en ook laat de Javaansch-Mohammedaansche dagteekening bezwaarlijk aan een' Balineschen oorsprong denken. Daar het evenwel ook niet beantwoordt aan hetgeen RAFFLEs t. a. p. -

1 Aangenaam is het mij te mogen mededeelen, dat het Bestuur van 't Kon. Instituut zich genegen verklaard heeft, behoudens toestemming van de $R$. A. Society, de onder No. 5 bedoelde proeven van oud Jav. schrift, benevens eene proeve van den Falak Bosdha, voor zijne rekening in lithographische facsimile's uit te geven. 
blijkbaar te algemeen - van "de Javaansche handschriften der B. J. $K w$." zegt, onderstel ik, dat het eerst later in zijn bezit gekomen is.

De MSS., die voorheen in 't East India house bewaard werden, zijn thans overgebragt naar India office (Cannon row, Whitehall). Ook daaronder bevond zich, onder $\mathrm{N}^{\circ}$. 15 , eene $B$. $J$. $K w$, , en wel met Jav. verklaring, maar slechts de eerste helft, waarvan ik reeds genoeg MSS. had. De opgave van den heer KEIJZER, dat er van voren verscheiden bladen aan dit handschrift ontbreken, moet ik voor eene vergissing houden, welligt te wijten aan de omstandigheid, dat er vóor het begin van de $B . J$. nog eenige beschrevene bladen ingebonden zijn, die aan ' $t$ geheel bij oppervlakkige inzage het voorkomen geven van 't begin te missen.

Omtrent de overige nommers van de lijst van den heer KEIJZER valt nog op te merken: dat de beschrijving van $\mathrm{N}^{\circ}$. 28 en 38 onderling verwisseld behoort te worden, zijnde namelijk het laatste de "geschiedenis van sÉLå BĕRÈT, Vorst van Tjëmpå," terwijl het eerste "verschillende defecte poëtische stukken" bevat; dat voorts $\mathrm{N}^{\circ} .36$ twee deelen, $\mathrm{N}^{\circ} .37$ daarentegen maar één deel heeft; №. 45 o. a. de geschiedenis van Rådjå NOERsÉwAN van Madajin, $\mathrm{N}^{\circ} .46$ die van Dåså-RåTå (en RåMå?) bevat; en aan 't slot van de lijst nog ontbreekt $N^{\circ}$. 50 , bevattende verschillende stukken.

Zulke kleine onnaauwkeurigheden zijn bij 't beschrijven van eene verzameling handschriften, die men naauwelijks den tijd heeft even in te zien, bezwaarlijk te vermijden, en zullen ook in de tegenwoordige opgaven voorzeker niet ontbreken. Op de plaats zelve had ik geen' tijd om ze behoorlijk uit te werken, en moet het daarvoor thans ten deele op het geheugen laten aankomen. Ik meen mij evenwel door het besef van de onvolkomenheid mijner anteekeningen niet te moeten laten terughouden van te geven, wat ik heb kunnen bijeenbrengen.

In India office dan werden mij, buiten de door den heer KEIJZER beschrevene, nog eenige handschriften en papieren, tot onze Indische bezittingen betrekkelijk, vertoond, als behoorende tot de uitgebreide Mackenzie-collection. Een gedeelte daarvan, dat in de Record room (aan 't einde van den eersten gang, regts van den hoofdingang van 't gebouw) behoorlijk genommerd en gerangschikt stond, in eeine kast in den Z. O. hoek, bij 't venster, bevatte de volgende stukken. Die met een 
sterretje gemerkt, zijn in 't Engelsch geschreven, de overige , voor zoover de taal niet uitdrukkelijk vermeld is, in 't Hollandsch. In de inhoudsopgaven moet over 't algemeen, wat cursief gedrukt is, geacht worden woordelijk aan titel of opschrift der MSS. zelve ontleend te zijn, het overige als mijne beschrijving beschouwd worden, zonder dat evenwel op die onderscheiding onbepaald staat te maken valt.

*1. Krijgskundige memorie over Batavia, gerigt' aan den Gouverneur-Gen. ALting, uit het Holl. (zie $n^{0} .44$ ); benevens nog twee Fransche stukken over hetzelfde onderwerp.

*2. Verschillende stukken betrekkelijk de geschiedenis van Java.

*3. Beschrijving van Groot Java (uit het Holl. van vaLentiJn?)

*4. Affairs of the Molucca islands (vertaald uit valentiJn).

*5. A collection of all the contracts and documents containing privileges granted by native princes (van tegenwoordig Britsch Indië) since 1612 .

*6. The old and new East India's: Banda etc. (vertaald uit vaLENTIJN).

*7. A history of the discovery etc. of Ceylon (uit het Holl.?).

*8. An account of Solo or Suracarta and its Susuhunan or emperor, 1812; - met nog eenige stukken over dezelfde onderwerpen.

*9-7, met nog eenige stukken over Ceylon.

*10. Eenige opstellen van verschillende schrijvers over Java's aardrijkskunde, geschiedenis, natuurgesteldheid, enz.

*11. A description of the Molucca islands (van valentiJn?)

*12. Correspondence of Col. Mackenzie, Java 1812.

13. Div. stukken over Malabar, enz. 1767.

14. Dito dito over Ceylon, 1793-7.

*15. Klad van eene geschiedenis van Java, 1813.

*16. General report of the Commission for inspecting the upper districts near Batavia, 1808 (uit het Holl.?).

16 bis. Djåjå Lěnkårå: Jav. dichtwerk.

17. Watoe Goenoeng: als voren, met gekleurde teekeningen, grevolgd van eene Hollandsche vertaling door G. w. vincent. *18. Geschiedenis van Java, Malakka en Sumatra, vertaald uit VALENTIJN. 
*19. Verschillende stukken over Java: oudheden; buskruidfabriek te Samarang; div. verslagen.

*20. Eene verhandeling over de studie der geschiedenis, uit het Holl. van J. VAN IPEREN; - vertaling van eene Jav. genealogie, met aanteekeningen, uit het Holl. van denzelfde; - ontwerp van een' brief.

*21. Beschrijving van Ceylon, met een uittreksel uit vALENTIJN's beschrijving van dat eiland, enz.

22. Onvolledige woordenlijst, Engelsch, Holl., Fransch, Maleisch en Javaansch.

*23. Sadjarah radja Djawa: eene Jav. genealogie, uit het Jav. door GORDON, 1813, met aanteekeningen door J. vAN IPEREN, vertaald uit het Holl. van de Verhandelingen van 't Bataviaasch genootschap van Kunsten en Wetenschappen; - benevens div. stukken betrekkelijk de geschiedenis van Java.

24. Geschiedeuis van Watoe Goenoeng, uit het Jav.

25.)

26. Niet voorhanden,

27.)

*28. Beschrijvingen van Makasser, Borneo, Bali en Siam, vertaald uit VALENTIJN.

*29. Report of the commission for East India affairs to the State directory of the Batavian republic, 1803, uit het Holl. of Fransch.

30. Onvolledig Jav. geschrift, handelende over Rådjå Mangsahpati van Wiråthå.

31. Memorie over Coromandel, 1738.

32. Div. defecte Jav. stukken.

*33. Vertaling uit het Holl. van eenige Jav. stukken over mythologie, Adji Såkå, enz.

34. Lijst van "speculative papieren" over div. onderwerpen van bestuur, handel enz. in Indië, 1811; met Eng. vertaling.

35. Register van contracten, boeken en papieren van 't voormalig Ned. bestuur in Indië, berustende in 't Gouvernementsarchief te Batavia.

36. Verslagen van den Gouverneur-Gl. Mossel over zaken van handel in Nagapatnam, Coromandel en Bengalen, 1739.

37. Vragen en antwoorden over eenige twijfelachtige punten betreffende de huishouding enz. der olifanten, 1787 .

38. Memorie over den staat der Wanni-landen op Ceylon, 1793. 
39. Vertalingen uit Jav. geschriften over mythologische onderwerpen.

40. Klad van 't vorige, voorafgegaan van een opstel over de geographie van Java.

41. Sěrat kåndhå ringgit poerwå: Jav. wajangspelen in prosa.

42. Papers found in Fort Lodewijk, Sept. 1811: Fransche - en Hollandsche brieven over krijgszaken.

*43. Instructions for residents of out stations (uit het Holl.?), - en diverse andere stukken.

44. Krijgskundige memorie over Batavia, 1ste stuk.

45. Div. memoriën over zaken van Ned. Indië.

*46. Lijst van wegen op Ceylon, - en div. andere stukken over dat eiland, - uit het Holl.?

*47. A table of books, papers and registers concerning the Dutch affairs in E. I., found on an inspection of the archives of the former government.

*48. Div. vertalingen en uittreksels: Geschiedenis van Groot Java; Jav. oudheden; beschrijving van de uitbarsting van een' vuurberg op Java; over een koortswerend middel; begin van eene geschiedenis van Amboina, uit RUMPHUUs. *49. Kerkelijke zaken van Amboina, uit valentiJn.

*50. Memorie over Coromandel, 1716.

*51. Verslag over de zaken van Ned. Indië, 1803 (uit Holl. of Fransch).

*52. Duplikaat van No. 1.

*53. Verslag over Jakatra en de Preanger landen op Java, 1808 (uit het Holl.).

*54. Zaken van godsdienst op Java (uit valentiJn?).

55. Java zo als het is, en zo als het kan zijn: eene memorie aan RAFFLES, 1812.

*56. ValentiJn's reizen naar Oost-Indië, uit het Holl.

*57. Div. stukken over Bantam, Jakatra enz., uit het Holl.

58. Div. defecte Jav. stukken.

*59. Div. stukken over zaken van Java.

*60. Notices and remarks on some districts of the East of Java, 1812-3, uit het Fransch.

61. Babat Sakandar, a Malay MS. (in Eur. schrift), copied at Surabaya, 1814, - bevattende o. a. een fabelachtig verhaal van de eerste vestiging van Europeanen op Java.

62. Periodicque bespiegelingen over de defensie van Batavia, 1801. 
*63. Memorie over Samarang en de N. O. Kust van Java, uit het Holl. van 1761 ; - eene $d^{\circ}$. uit het Fransch? vertaald 1812 .

64. Ontbreekt.

65. Klad van Holl. vertaling van een Jav. stuk over astrologische tijdrekening.

66. A collection of alphabets used in Juva, bevattende slechts een paar oude schriftvormen, waarvan een veel overeenkomst heeft met het alphabet $\mathrm{N}^{\circ} .4$ op plaat 21 van RAFFLEs' Atlas, ofschoon sommige letters geheel verschillend zijn ${ }^{1}$; een ander het meest gelijkt naar $\mathrm{N}^{\circ}$. 5 van die plaat of naar pl. 85; voorts een Pali alphabet gelijk het square Pali op pl. 22, en nog een alphabet, dat slechts in enkele letters min of meer overeenkomst toont met sommige alphabetten van RAFFLES; - overigens niets dan oefeningen in 't gewone, hedendaagsche Jav. schrift.

*67. Vertaling van een Jav. geschiedverhaal, van Adam tot het rijk van Mataram.

*68. Bucquoy's voyages to India, transl. from the Dutch, Harlem 1757.

*69.) Daendel's State of Netherlands E. 1. possessions, *70. 1808-11, 2 vol., - uit het Holl.

*71. Life of Susuhunan Amancu Rut (of Cartasura), uit het Jav. 1816.

*72.) Engelhard's Review of the state of Dutch E. I., 2 vol. *73. 1816 , uit het Holl.

*74. Brief met eenige opmerkingen betreffende eene memorie over den staat van Nederl. Indië, 1815: uit het Holl.? *75. $\mathrm{D}^{\circ}$. over het bestuur van koloniën, met beoordeeling van een werkje getiteld Java, Amst. 1816: - uit het Holl? *76.) Malabar letters, by Mr. Jacob Canter Visscher, 2 vol, , *77. Batv. 1724: uit het Holl.?

*78. A brief review of the former trade of the Dutch in Asia, by H. D. Campagne, Hague and Amst. 1816:- uit het Holl.?

*79. Voyage of J. J. de Roy te Borneo and Atcheen, Batv. 1698: uit het Holl.?

1 De hier en verder medegedeelde vergelijkingen heb ik eerst t'huis kunnen maken met behulp der kleine staaltjes van vreemde schriftvormen, die ik uit de MSS. tot nader onderzoek had opgeteekend. 
*80. The history of Susuhunan Amancu Rat of Cartasura: - uit het Jav.?

*81. H. van Quellenburgli's Vindiciae Batavicae, or Refu*82. tation of the treatise of Tavernier, Amst. 1684, 2 vol.: uit het Holl.?

*83. Answer upon a question proposed by the Dutch society of sciences at Harlem, over kanalen in Texel, enz.: uit het Holl.?

*84. De Chinesche oorlog op Java: uit het Jav.?

*85. Uittreksel uit vaLENTIJN's beschrijving van Groot Java, uit het Holl.

*86. Div. stukken over het bestuur van Java.

*87. Berigt van Sumatra, Borneo en Ceylon, door A. eschelsKROON, uit het Hoogduitsch, Haarlem 1783.

*88. $~^{\circ}$. van Holl. handelsplaatsen in Indië: uit het Holl.?

*89. Vertaalde uittreksels uit de Bataviasche couranten, 1818-9.

*90. Geschiedenis van RAMa, uit het Jav.

Bestaat deze verzameling grootendeels uit Engelsche vertalingen van Holl. geschriften, en andere stukken, die hier slechts volledigheidshalve vermelding verdienen, meer waarde schijnt voor ons te schuilen in een ander gedeelte van de Mackenzie collection (?), dat echter helaas, in den ordeloozen staat, waarin ik het aantrof, geene geregelde beschrijving, met de noodige aanwijzing tot het terugvinden van ieder stuk, toelaat. Men bragt mij van elders in de Record room een hoop MSS., deels ingenaaid, deels in losse papieren, tot pakketten van zeer gemengden inhond zamengebonden, eenige genommerd, andere niet, enkele ook, die tot O. I. in 't geheel geene betrekking hadden. Bij eenige meerdere ruimte van tijd zou 't mij zeker niet aan de vergunning ontbroken hebben, om er zooveel orde in te brengen, als noodig was, om er een' bruikbaren catalogus van te maken; maar dit zou mij te lang hebben opgehouden; en, in de hoop, dat eenig ander zich daartoe zou kunnen verledigen, meende $\mathrm{ik}$, dat het toch reeds eenig nut kon heb. ben, voorloopig zoo goed mogelijk op te teekenen, wat ik vond, en in welken staat ik het vond. I $k$ heb tot dat einde elk pakket geopend, vlugtig doorgezien, en weder gesloten zoo als ik het gevonden had, en geef hier den inhoud in de 
volgorde, waarin de stukken mij ter hand kwamen, zonder mij te storen aan de volgorde der eijfers, die ik er slechts ten gemakke der herkenning bijvoeg, waar ik ze aautrof. Zoolang toch geene betere rangschikking van de stukken zelve heeft pluats gehad, zou een nader onderzoek slechts bemoeijelijkt worden door eene andere volgorde in mijne opgaven. Overigens gelden ten aanzien van deze lijst dezelfde onderscheidiugen als voor de vorige.

Eene woordenlijst, Maleisch, Javaansch, Madureesch, $8^{\text {vo }}$.

Eene dito, Engelsch, Maleiseh, klein $4^{\text {to }}$.

Eene dito, Javaansch, Kawi, Maleisch, Engelseh, zeer onvolledig, $4^{\text {to }}$.

Ontwerp van eene Maleische spraakkunst (in 't Engelsch?); - eenige Burmnesche en andere stukken, fol.

Een MS, in fol., dragende tot opschrift "Arabie-Bugis 1661

- 1696": schijnt journalen van ontvangsten en uitgaven of iets dergelijks te bevatten.

Een dito in fol., Boeginesche tekst, met Eur. dagteekeningen in Arb. schrift boven elke blz., 1776-1794.

Eene woordenlijst in fol.: Siameesch? het schrift schijnt ongeveer hetzelfde als dat bij RAFFLEs, pl. 22 , als modern Siamese voorkomende.

*Berigten over Borneo, door Kpt. ross, aan raffles, $4^{\text {to }}$. *Spraakkunst en woordenlijst van de Burmesche en Siamesche talen, 2 vol., fol. (onvolledig?).

${ }^{*} \mathrm{~N}^{0}$. 107. Malay and Burmese vocabulary, 4 vol. in fol.: schijnt minder Maleisch dan Siameesch te bevatten, en in een van de deelen Malayalam en nog eene andere taal, in onderscheiden letterschrift.

*Maleisch-Engelsche woordenlijst, fol.

$\mathrm{N}^{0}$. 47. Kanda-purwa: een Jav. verhaal in dichtmaat, beginnen met de geschiedenis van BASOEDÉwå van Madura en GORåWåNGså van Giling Wesi; - voorafgegaan van eenige Jav. brieven en andere schrifturen; - fol. op Jav. papier. Een pakket houdende 't volgende:

${ }^{*}$ No. 53. Een bundel brieven van en naar Makassar, Java en Madura, met finantiële staten, 1814.

97. Gedeelte van eene woordenlijst van verschillende talen op Sumatra, in Europ. schrift. 
*57. Particuliere brieven van RAFFles aan Lord Minto, $1810-1$, klein $4^{\text {to }}$.

*48. Memorandum of proceedings on the arrival of commissioners from Holland for resuming the colony, 1816, fol.

*124. On the Malayan nation, with a translation of their maritime code, fol.

*152. Over eene voorgenomene verbinding tusschen Innidad (?) en Bengalen.

Een pakket houdende:

* No. 132. Verslag van eene reis naar de binnenlanden van Sumatra, door T. BARNES, fol.

* 91. Een bundel brieven, getiteld: “Mr. Light regarding Queda," 1786, fol.

*183. Reply of the Bengal government to Baron van der Capellen regarding Singapore, 26 June-1819, fol.

* 199. Brief van Baron vaN der Capellen aan 't Bestuur van Bengalen, over het hijschen van de Engelsche vlag te Djohor, 6 Mei 1823, fol.

*138. Geschiedenis van den Vorst van Indrapoera, uit het Maleisch, door RAFFles, fol.

*221. Verslag van eene reis in de Batta-landen, door BURTON en WARD, 1824.

* 98. Woordenlijst, Menankabausch en Engelsch.

134. Maleisch verhaal van den Chineschen oorlog op Java, in Eur. schrift, fol.

Een pakket, houdende:

*No. 51. Papers and letters relating to the Molucca's: ook over Java, Billiton, Malakka, enz.

*165. Vertaalde brieven van den Sultan van Palembang.

*192. Briefwisseling tusschen RAFFLes en VAN DER CAPELLEN, Batv. Junij 1823.

*186. Dépèche van Raffles aan G. Dowdeswell, Fort Marlborough, 12 Aug. 1818.

* Report of a committee to inquire into the condition of the native population of Bencoolen, to Raffles, 2 Oct. 1819. *Kritische verhandeling naar aanleiding van CBAwFURD's History of the Indian archipelago en eenige andere werken van verwanten aard.

Div. brieven, dépèches, enz. 
Verslag van de zending naar Japan aan 't Bestuur van Java, 20 Dec. 1813.

Jav. MS. in $4^{0}$, , betiteld Poorvali (Pårå wali): verhaal in dichtmaat over de wali's, apostels van den Islam op Java.

108. Een MS. in fol., betiteld Vocabulary: schijnt te bevatten oefeningen in Sanskritische spraakkunst, en zamenspraken en spreekwijzen in Malayalam.

Wukun (Pawoekon): Jav. geschrift over astrologische tijdrekening met afbeeldingen, en Maleische vertaling in Eur. schrift, groot fol.

Different Javanese characters, bevattende eenvoudig oefeningen in gewoon Jav. schrift, groot fol.

Een pakket, houdende:

*2 ex. Aanmerkingen op een artikel in Edinburgh Review over MARSDEN's Maleische spraakkunst en woordenboek, door JAMBulos, Java 1815.

* Statistische opgaven over Japara en Koedoes, 1812.

*Verslag van eene commissie over zaken van Benkoelen.

* Briefwisseling van RAFFLes met inlandsche vorsten van Sumatra en Malakka; tractaten en andere stukken betrekkelijk het Ned. en Britsch Bestuur op Sumatra, 1811-5.

*242. Verslag van de grondlegging der Engelsche vestiging te Singapoera.

*Appointment of commissioners to take possession of Palembang, 1811.

Een pakket houdende:

Woordenlijst, Kawi en Javaansch, groot fol.

Dito Siameesch? gr. fol.

Twee cahiers met facsimile, Jav. transscriptie en vertaling van eenige oud Jav. inscripties; eene (volgens de transscriptie) met het jaartal 841 (= A. D. 919-20?), waarvan 't schrift ongeveer overeenkomt met dat van RAFFLES, pl. 85 (specimen of the Kawi character from an inscription on one of the copper plates deposited in the Museum of Arts and sciences at Batavia, supposed date about the Javanese year 700), zonder evenwel, naar 't schijnt, dezelfde inscriptie kunnen zijn, die R. bedoelt; - de andere, volgens de transscriptie van 864 (= A. D. $942-3$ ?), in een schrift, dat eenige overeenkomst, maar ook veel verschil, toont met R. pl. 21 , No. 4 . 
*223. Burns, brieven over Pontianak.

*260. Missive naar Bengalen over het tractaat van 1824 met Nederland.

* Memorie of opstel over het bestuur van O. I., zonder datum of onderteekening.

*190. Missive van 't Bestuur van Bengalen over Banka en Palembang, 15 Mei 1812.

* 52. Div. stukken betrekkelijk de verovering van Java, 1811. *158. Verordeningen betrekkelijk het regtswezen in Benkoelen. *238. Brieven aan Lord Minto.

*226. Memorie van RafFles, houdende ' $t$ voorstel tot verovering van Java, 1810.

*Div. brieven, dépèches enz.

*Briefwisseling van RAFFLes met Lord Minto, 1813-4.

Een pakket houdende:

*219. Verslag over Patjitan, volgens opschrift "very interesting", 1812 ?

*157. Vertaling van Maleische wetten van Benkoelen.

*135. Sketch of the Eboes (in Africa), collected from some slaves of that nation, 1796.

*231. 2 ex. Memoir on the value of the Dutch possessions in the E. I., and as to the mode of administering in case of being annexed to the British power, written before the expedition to Java.

*173. An account of Poggy isles.

*178. Eenige stukken betreffende Poelo Nias: tractaat met de inlandsche vorsten, enz.

Div. brieven: officiëel en partikulier.

An account of the proceedings of the Wali-wali or Islamite apostles in Java; volgens een ander, Maleisch opschrift: Kitab sadjarah nabi-nabi dan doa-doa, d. i. geslachtlijst van profeten, en gebeden, - in Jav. taal met Arb. karakter.

Wetten van Malakka, in 't Maleisch.

Hikajat tanah Djava: Maleische geschiedenis van Java, met gedeelte van Eng. vertaling, fol.

Chondro senkolo (Tjåndrå-sěnkålå): Jav. tijdtafel.

Eenige Jav, en Maleische stukken van gemengden inhoud. Een geschrift in onbekend karakter (Malayalam?).

Succession of the Datu's of Luwu, in 't Maleisch.

Een Jav. geschrift, betiteld Koontoro, Jookol Moodo and 
Telogo Ening (KoEnTHåRå, DJOEGOEL MOEDHå, TĕLåGå ĕNING).

Een dito, houdende eenige tijdsopgaven uit de geschiedenis van Java.

Een dito, betiteld Koenthårå.

Een dito, over zedeleer?

Een dito, Soerjå Ngalam.

Een Maleisch geschrift, hebbende tot opschrift: Ini segala obat, or the Malay Materia medica, from the practice of Jama, physician to the Royal household of H. M. of Pontianac, copied March 1813; en in Arb. karakter: Kitab obat-obat azimat, d. i. beschrijving van genees- en toovermiddelen.

Transscript of an ancient MS. found in Cheribon, and three others, whence and subject unknown.

Het schrift van al die MSS., of althans van drie, is oogenschijnlijk hetzelfde, ongeveer gelijk aan dat van den boven beschreven Falak Boedha; ja welligt - wat bij vergelijking spoedig ware uit te maken - hebben wij hier een facsimile van 't zelfde Tjeribonsche MS., waarvan de Falak B. is afgeschreven: althans een van de bedoelde MSS. heeft, langs de linkerzijde, figuren van draken en dergelijke, even als wij ze in den $F . B$. aantroffen; een ander prijkt met menschenbeelden in den trant der wajangpoppen.

*Mr. Burton's account of the language, literature and laws of the Batta's, met een' brief, gedagteekend van Si. boga, Maart 1824.

*224. Over wetten en gebruiken van de Batta's.

*Inleiding tot een Battaasch woordenboek.

*Vertaling van een Maleisch berigt betrekkelijk de “ $M e l$ lums" of Padri's.

*Woordenlijst, en vertaling van eene inlandsche geschiedenis van Java, kl. $4^{\text {to. }}$

Facsimile van eene Kawi-inscriptie op koper, berustende in 't Museum van 't Bataviaasch Genootschap, gevonden in 't oostelijk deel van Java: het schrift (en waarschijnlijk de inscriptie zelve?) = RAFFLES, pl. 85 .

Dito van eene inscriptie op steen, van gelijke afkomst, met vertaling in hedendaagsch Javaansch); - bovenaan een menschenbeeld; jaartal volgens de verklaring 1056 
(= A. D. $1134-5$ ? ): het schrift niet met zekerheid bij RAFFLES herkend.

Dito van eene inscriptie van Pekalongan, zonder verklaring: schrift ongeveer = RAFFLES, pl. 84 (facsimile of an inscription on stone found in the district of Pakalungan).

Dito van eene inscriptie op steen van Magĕlang.

Dito van eene inscriptie, in de levende rots gehouwen te Chandioso (Tjandiyåså?) in Kadhoe.

Hiertoe bepaalt zich, wat ik gevonden heb. Veel, wat hier kortheidshalve onder onbepaalde uitdrukkingen als "diverse" is zamengevat, had wel eene nadere specificatie verdiend. Is er aan den anderen kant onder het medegedeelde ook veel, wat naauwelijks onder de "bronnen" mag gerekend worden; is ook datgene, wat oppervlakkig meest belangrijk scheen, reeds grootendeels, en welligt nog meer dan mij bekend is, door vroeger onderzoek en benuttiging als uitgeput te beschouwen, toch mag het zeker hoogst wenschelijk heeten, dat eene verzameling, die in zoo naauwe betrekking staat tot de taal-, landen volkenkunde onzer tegenwoordige en voormalige bezittingen in O. I., door eene betere beschrijving, en, voor zooveel noodig, door eene betere rangschikking, meer in het bereik van den Nederlandschen onderzoeker gebragt wierd. Mogten mijne gebrekkige mededeelingen daartoe slechts tot aanleiding dienen, dan zou ik mij de daaraan bestede moeite niet hebben te beklagen.

's Gravenhage, September 1862. 